Review began 09/30/2021 Review ended 10/03/2021 Published 10/06/2021

\section{() Copyright 2021}

Ashok et al. This is an open access article distributed under the terms of the Creative Commons Attribution License CC-BY 4.0. which permits unrestricted use, distribution, and reproduction in any medium, provided the original author and source are credited.

\title{
Role of Vitamin B12 and Folate in Metabolic Syndrome
}

Tejaswini Ashok ${ }^{1}$, Harivarsha Puttam ${ }^{2}$, Victoria Clarice A. Tarnate ${ }^{3}$, Sharan Jhaveri ${ }^{4}$, Chaithanya Avanthika ${ }^{5,6}$, Amanda Guadalupe Trejo Treviño ${ }^{7}$, Sandeep SL ${ }^{8}$, Nazia T. Ahmed ${ }^{9}$

1. Internal Medicine, Jagadguru Sri Shivarathreeshwara Medical College, Mysore, IND 2. Internal Medicine, Employees State Insurance Corporation Medical College and Hospital, Hyderabad, IND 3. Medicine, Far Eastern University Nicanor Reyes Medical Foundation, Quezon City, PHL 4. Internal Medicine, Smt. Nathiba Hargovandas Lakhmichand Municipal Medical College, Ahmedabad, IND 5. Medicine and Surgery, Karnataka Institute of Medical Sciences, Hubli, IND 6. Pediatrics, Karnataka Institute of Medical Sciences, Hubli, IND 7. Medicine, Facultad de Medicina Universidad Autonoma de Nuevo León, Monterrey, MEX 8. Internal Medicine, SRM Medical College Hospital \& Research Centre, Kattankulathur, IND 9. Medicine, Shahabuddin Medical College and Hospital, Dhaka, BGD

Corresponding author: Chaithanya Avanthika, avanthika.chaithanya@gmail.com

\section{Abstract}

Metabolic syndrome (MS) is a collection of pathological metabolic conditions that includes insulin resistance, central or abdominal obesity, dyslipidemia, and hypertension. It affects large populations worldwide, and its prevalence is rising exponentially. There is no specific mechanism that leads to the development of MS. Proposed hypotheses range from visceral adiposity being a key factor to an increase in very-low-density lipoprotein and fatty acid synthesis as the primary cause of MS. Numerous pharmaceutical therapies are widely available in the market for the treatment of the individual components of MS. The relationship between MS and vitamin B complex supplementation, specifically folic acid and vitamin B12, has been a subject of investigation worldwide, with several trials reporting a positive impact with vitamin supplementation on MS.

In this study, an all-language literature search was conducted on Medline, Cochrane, Embase, and Google Scholar till September 2021. The following search strings and Medical Subject Headings (MeSH) terms were used: "Vitamin B12," "Folate," "Metabolic Syndrome," and “Insulin Resistance.” We explored the literature on MS for its epidemiology, pathophysiology, newer treatment options, with a special focus on the effectiveness of supplementation with vitamins B9 and B12.

According to the literature, vitamin B12 and folate supplementation, along with a host of novel therapies, has a considerable positive impact on MS. These findings must be kept in mind while designing newer treatment protocols in the future.

Categories: Endocrinology/Diabetes/Metabolism, Internal Medicine, Epidemiology/Public Health Keywords: insulin resistance, cardiovascular disease, nutrition and metabolism, obesity and diabetes, vitamin b supplementation, folic acid supplementation, vitamin b12 supplementation, diabetes and metabolic syndrome

\section{Introduction And Background}

Metabolic syndrome (MS) is one of the most debilitating disorders currently affecting large populations worldwide, with its prevalence rising exponentially. MS refers to a group of pathological metabolic conditions including insulin resistance, central or abdominal obesity, atherogenic dyslipidemia, and hypertension [1]. According to the Adult Treatment Panel III (ATP III) classification, the parameters of MS include waist circumference of $>102 \mathrm{~cm}$ for men and $>88 \mathrm{~cm}$ for women, fasting blood glucose of $>6.1$ $\mathrm{mmol} / \mathrm{L}$, blood pressure of $>135 / 85 \mathrm{mmHg}$, triglyceride level of $>1.7 \mathrm{mmol} / \mathrm{L}$, and high-density lipoproteincholesterol (HDL-C) level of $<1.0 \mathrm{mmol} / \mathrm{L}$ [2]. The diagnosis of MS is established if an individual meets three of these five parameters [2]. MS, also known as insulin resistance syndrome, syndrome X, as well as the deadly quartet, has been recognized as an important risk factor for the development of cardiovascular disease and type 2 diabetes mellitus, with an estimated two-fold and five-fold increased incidence risk, respectively [3]. By 2030, approximately $38 \%$ of the adult population globally is predicted to be overweight and roughly $20 \%$ to be obese, which increases the prevalence of morbidity caused by chronic diseases [4]. Numerous pharmaceutical therapies are widely available in the market for the treatment of the individual components of MS, such as statins, antihypertensives, and antidiabetic drugs. Meanwhile, suggested dietary supplements are also available, such as folic acid and vitamin B12, which may be beneficial in the treatment of MS.

Vitamins B9 (folate) and B12 (cobalamin) are essential water-soluble vitamins that serve an important role in DNA methylation and the homeostasis of both amino acids and lipids through the regulation of onecarbon metabolism [5]. One-carbon metabolism is a chain of interconnected biochemical pathways mainly powered by folate and methionine to generate methyl donors utilized by several cellular processes [5]. Because vitamins B9 and B12 are crucial for cell metabolism, their deficiency can lead to alarming health 
consequences.

Low levels of folate and cobalamin can cause DNA synthesis interference, cellular inflammation, and elevated synthesis of fat and homocysteine [6]. Homocysteine is a non-proteinogenic amino acid produced by the breakdown of dietary proteins such as methionine [7]. Hyperhomocysteinemia can contribute to the development of cardiovascular and cerebrovascular diseases due to atherosclerotic vascular-endothelial injury [8], as well as the development of insulin resistance [9]. Studies have shown that folic acid, vitamin B12, and other B-complex supplements are effective in reducing homocysteine levels in the plasma [10], thus leading to the reduction of the prevalence of MS.

The relationship between MS and vitamin B complex, specifically folic acid and vitamin B12, has been the subject of many studies worldwide. Several studies have reported a positive association between the supplementation of folic acid and vitamin B12 and their effectiveness in the reduction of cardiovascular disease [11] and insulin resistance [12]. The scope of this literature review is to study and analyze scientific articles from PubMed and other academic journal libraries regarding the possible role and effectiveness of folic acid and vitamin B12 in MS patients. By reviewing the efficacy of folic acid and vitamin B12 supplementation in MS, we aim to enumerate potential recommendations which can be added to the current treatment regimen for MS patients. However, considerations of additional studies, such as those relating to the appropriate frequency, duration, and dosage of folic acid and vitamin B12 as an adjunct for MS treatment, will need to be evaluated to prevent any unwanted adverse effects.

\section{Review}

\section{Sources, metabolism, and interactions}

Sources

It is important to shed light on the dietary sources of folic acid and cobalamin, being vitamins of public health significance. Excellent sources of vitamin B9 (folate) are green leafy vegetables, citrus fruits, pulses, cereals, liver, and egg yolk while vitamin B12 is majorly present in meat, eggs, milk, dairy products, fish, and shellfish, with the concentration of cobalamin varying within the food of ruminant origin with the highest concentrations found in offal such as liver and kidney. Various studies have been conducted to measure the adequacy of dietary intake of folic acid and cobalamin in different populations owing to its key function in the one-carbon metabolism and its clinical significance [13,14]. In Europe, a study demonstrated subclinical deficiency of vitamin B9 and B12 to be prevalent in 20\% of adolescents [15]. Correspondingly, nutritional data surveys conducted in cross-country comparative studies across the European continent showed a mean prevalence of inadequacy at or below $10 \%$ for the elderly and below $20 \%$ for the adult population [16]. Remarkable differences have been noted in vitamin B12 levels in cohort studies of meat eaters, fish eaters, vegetarians, and vegans, highlighting the inadequate dietary intake among vegans and vegetarians [17,18]. Attempts have been made to identify naturally occurring cobalamin-rich, plant-derived foods, such as dried shiitake mushroom fruiting bodies, dried green laver (Enteromorpha species) and purple laver (Porphyra species), aquatic plant Wolffia globosa (Mankai), sea buckthorn (Hippophae rhamnoides) berries and granulate products, and sidea couch grass (Elymus repens) products (dry extract and ground) [19-22]. A clinical trial conducted in India to determine improvement in vitamin B12 status among deficient vegetarians with dairy cow's milk intake concluded that it can drastically improve blood cobalamin levels [23].

Finding new methods that increase cobalamin content in vegetarian diets has been an important field of research. Two such effective methods are the addition of cow manure to significantly increase the vitamin B12 content of spinach leaves and the fermentation of food with lactic acid or propionic bacteria [19]. Another strategy aimed to enrich animal products with natural folic acid through the addition of high doses of synthetic folic acid to animal feed. In another study, supplementation of hen's diet with folate enriched hen's eggs to a maximum folate content of approximately 2.5 times that of a normal egg [24]. Increasing fiber concentration of cow's diet was positively associated with vitamin B12 concentration in milk, whereas a negative relationship was established between folate and dietary fiber concentrations $[25,26]$. Furthermore, intramuscular injection of vitamin B12 in early-lactation dairy cows increased vitamin B12 content in milk [27].

The association of impaired folate levels with various pathological consequences led to the initiation of exogenous supplementation and biofortification approaches. Interventional trials aimed at proving the linkage of maternal vitamin B12 consumption with the concentration of vitamin B12 in breast milk showed that vitamin B12 concentration in human milk can be modified via supplementation during periconceptional and lactational periods [28]. Implementation of mandatory fortification of cereal grains with vitamin B12 was attempted in 1998 in the United States, followed by several other countries in subsequent years. However, despite evidence of the benefits of fortification, concern has been raised regarding the detrimental effects of exposure to synthetic or crystalline folic acid, the most important being the masking of vitamin B12 deficiency and its progression leading to irreversible neurological deficits [29]. 
and quadruple fortification (iron, iodine, folic acid, vitamin B12) has been undertaken recently [30,31]. With increasing attention on the nutritional benefits of insects, the folic acid content in two cricket species, namely, Scapsipedus icipe and Gryllus bimaculatus, was measured and found to be much higher than animal and plant-based food sources, making crickets a cheaper alternative as opposed to commercial supplements. This demonstrated the need for the inclusion of crickets into the human diet, especially in resource-poor populations [32]. In a study directed at isolating strains of lactobacilli synthesizing the highest folate concentration by milk fermentation, it was found that Lactobacillus fermentum (from kefir granules), Lactobacillus plantarum (from salted mustard), and Lactobacillus rhamnosus (from breast milk) produced the highest concentrations of folic acid in the absence of pre-existing folate in milk [33]. An interventional study conducted in India to estimate the potentiality of tea as a scalable vehicle for fortification with vitamins B9 and B12 successfully showed that the daily consumption of a cup of vitamin-fortified tea for two months could benefit women of reproductive age [34]. Investigations on the dietary value of freshwater living green unicellular algae Chlorella species proved the presence of large amounts of folate. Moreover, a meta-analysis on the effect of its supplementation on cardiovascular risk factors showed that it improves total cholesterol levels, low-density lipoprotein-cholesterol (LDL-C) levels, systolic blood pressure, diastolic blood pressure, and fasting blood glucose levels [35].

With the advent of metabolic engineering, new studies are being conducted to assist in the construction of microbial cell factories for large-scale vitamin B12 production [36]. All these studies have the common goal of finding ways to improve folate and cobalamin levels in the general population, thus emphasizing the importance of these vitamins in the prevention of avoidable hematological and neurological complications.

\section{Metabolism}

Understanding the metabolism and the effects of alterations in each of its steps is of utmost importance as it would help us interpret and prognosticate the pathological outcomes and therapeutic possibilities. The metabolic processes of vitamins B9 and B12 are complex and interrelated at the cellular level. Following the breakdown of cobalamin, its reduced form is directed toward the two enzymes, namely, cytosolic methionine synthase and mitochondrial methylmalonyl-coenzyme A mutase (MUT) [37]. MUT utilizes an adenylated form of cobalamin in the catabolism of branched-chain amino acids, odd-chain fatty acids, and the side chain of cholesterol, whereas methionine synthase requires a methylated form of cobalamin and catalyzes the remethylation of homocysteine to methionine (using 5-methyltetrahydrofolate [CH3-THF] as a methyl donor) [37]. The methionine produced is further converted to S-adenosyl methionine (AdoMet, often called SAM), whose methyl group can be further donated to essentially important methylated compounds such as creatine, epinephrine, sarcosine, methylated DNA, RNA, and proteins [37].

The linkage of cobalamin metabolism with the folate-mediated one-carbon metabolism is attributed to the utilization of CH3-THF as the methyl donor [37]. CH3-THF is the most common form of folate in blood and tissues [38]. Depending on the cellular requirements, the folate-mediated one-carbon metabolic pathway helps folate to interchange between its different forms.

This metabolic pathway is mainly compartmentalized between cytosol and mitochondria depending on the mono/polyglutamate tail of folate which serves as a localization signal within the cell [39]. Even though two separated parallel pathways exist in cytosol and mitochondria, mitochondrial one-carbon oxidation accounts for approximately $50 \%$ of the nicotinamide adenine dinucleotide phosphate produced in the cell [40]. The deficiency of vitamin B12 and/or folate leads to the disruption of the one-carbon cycle and its downstream metabolic processes. Therefore, a deeper understanding of the cause and effect of the onecarbon metabolism is essential to obtain considerable insights into its role in the development of metabolic diseases [41].

\section{Interactions}

Mammalian cells exhibit two different vitamin B12-dependent reactions: conversion of methylmalonyl coenzyme A to succinyl coenzyme A by the enzyme MUT and the methylation of homocysteine to methionine by methionine synthase. The deficiency of vitamin B12 results in elevated levels of homocysteine and methylmalonic acid in the circulation. These function as biochemical markers of vitamin B12 status. Studies have proven that excess folate resulting mostly due to high folic acid intake interferes with cobalamin metabolism and worsens conditions associated with vitamin B12 insufficiency [42].

Malabsorption of vitamin B12 among the elderly has been observed commonly due to gastric atrophy or as a result of Helicobacter pylori infection. Pernicious anemia due to lack of gastric acid and intrinsic factors is another cause of B12 malabsorption. Low gastrointestinal motility resulting from gastrointestinal surgery, including gastric bypass, jejunal diverticulosis, blind-loop syndrome after intestinal surgery, and structural abnormalities such as diverticulosis in the duodenum or jejunum lead to bacterial overgrowth in the upper intestine, which, in turn, impairs the absorption of vitamin B12 from food. The proposed mechanisms for this include competition with intestinal bacteria for the uptake of vitamin B12, bacterial conversion of the vitamin to inactive analogs, and hypochlorhydria [43,44]. Some of the infections interfering with vitamin B12 absorption are fish tapeworm infection, Giardia lamblia infection, malaria, human immunodeficiency 
virus infection, and acquired immunodeficiency syndrome [44]. Tropical sprue, celiac disease, ZollingerEllison syndrome, Imerslund-Gräsbeck syndrome, juvenile pernicious anemia, pancreatic insufficiency, and defects in haptocorrin binding proteins are some of the pathological conditions associated with reduced cobalamin absorption [44]. Chronic pancreatitis and cystic fibrosis result in impaired trypsin secretion which is required for the release of vitamin B12 from transcobalamin-1 in the intestine [44].

Drugs interacting with vitamin B12 absorption include histamine receptor antagonists such as famotidine and proton-pump inhibitors such as omeprazole and lansoprazole. Cimetidine has been shown to inhibit the secretion of gastric acid, pepsin, and intrinsic factors [45-47]. A dose-related effect of cimetidine on vitamin B12 absorption was observed with intakes $>1,000 \mathrm{mg} /$ day reducing food-bound vitamin B12 absorption, but not $400 \mathrm{mg} /$ day [45,48]. Similarly, a $20 \mathrm{mg} /$ day dose of omeprazole reduced vitamin B12 absorption from a protein-bound source by approximately $70 \%$, while $40 \mathrm{mg}$ /day reduced absorption by approximately $90 \%$ [49].

Moreover, mild transcobalamin I deficiency has been linked to the risk of low serum cobalamin concentration. A common gene polymorphism was observed in vitamin B12 carrier protein, transcobalamin II, where proline $(\mathrm{P})$ is substituted for arginine (A), affecting the mean total plasma concentrations of vitamin B12 and homocysteine [50]. Unlike folic acid, dietary folates are relatively unstable to oxidation and heat; hence, large losses can occur during food preparation and cooking. Boiling has been shown to destroy up to $80 \%$ of folate in green vegetables, whereas chopping and grinding spinach has been shown to increase folate bioavailability [51,52]. Furthermore, ascorbic acid in foods was shown to improve folate stability [53].

Chronic alcoholics are prone to vitamin B9 deficiency due to low folate intake, poor folate absorption due to impaired transcription of the intestinal folate carrier, reduced liver uptake and storage, and increased urinary excretion [54]. The speed of onset of alcoholic liver disease was assessed in a micro-pig model, which demonstrated that the onset was more rapid when the animals were provided with a folate-deficient diet than when folate intake was adequate [55]. Medications that impair folate status include methotrexate (a folate antagonist used in the treatment of rheumatoid arthritis, inflammatory bowel disease, etc.), anticonvulsants (phenytoin, phenobarbital, and Dilantin), sulfasalazine (for the treatment of chronic ulcerative colitis), and pyrimethamine (for the treatment of malaria), as well as large doses of nonsteroidal anti-inflammatory drugs [44]. The $677 \mathrm{C} \rightarrow \mathrm{T}$ (cytosine-thymine) gene polymorphism in methyltetrahydrofolate reductase was found to affect up to $30 \%$ of various population groups studied, mainly in developed countries, and the homozygote was associated with increased plasma homocysteine level and low serum and erythrocyte folate levels [56].

\section{Epidemiology of insulin resistance}

The worldwide incidence of MS ranges from $10 \%$ to $40 \%$ depending upon the region and the criteria used to define it [57]. The evolution of MS depends upon several factors such as obesity and insulin resistance [58]. These factors, in turn, result in an increased probability of type 2 diabetes mellitus [58,59]. Furthermore, a strong correlation exists between obesity, insulin resistance, and polycystic ovarian syndrome (PCOS) in women [60].

In the United States alone, the incidence of childhood obesity has nearly tripled from $7 \%$ to $18 \%$ between 1980 and 2013 [61]. Developing nations have also seen a 4.8\% rise in obesity from 1980 to 2013 [62]. In 2014, $13 \%$ of the adult population was obese [63]. Concurrently, there were reportedly 422 million insulin-resistant diabetics in the world [64]. These numbers are only expected to escalate in the future and are predicted to increase up to 649 million by 2040 [65]. It is important to note that there has been a significant number of diabetes-related deaths globally (1.6 million) [64]. Type 2 diabetes is also a common side effect of PCOS [66]. Approximately, $60 \%$ to $80 \%$ of PCOS-affected women suffer from insulin resistance [67].

\section{Pathophysiology of metabolic syndrome/insulin resistance}

There is no specific mechanism that leads to the development of MS. Multiple studies have reported that there is an association between insulin resistance and visceral adiposity [68]. Thus, being a state that predisposes to several comorbidities, additional clinical conditions such as hypertension and dyslipidemia may emerge. In addition, it can be seen as a condition in which there is an increment in both thrombotic and inflammatory states distinguished by an elevation in the inflammatory cytokine activity [69].

Insulin resistance is a decrease in the biological function of insulin, irrespective of the serum concentration [70]. Insulin resistance can be taken as the main pathophysiology of MS. Second, the increased prevalence of insulin resistance is related to the global increase in visceral adiposity [71]. Central obesity can emerge from multiple factors, such as an inappropriate diet of consuming higher processed calories, genetic predisposition, or epigenetic factors that can relate to the environment. Recently, a correlation has been reported between the high intake of fats and an inadequate function of the intestinal barrier that can ease the movement of intestinal luminal content and bacterial lipopolysaccharide into the circulation, which throws further light on its pathophysiology [72-74].

One of the main causes that develop this resistance mechanism is the excess of free fatty acids circulating 
from an expanded adipose tissue mass. This additional fat decreases the insulin sensitivity in the skeletal muscle by inhibiting the glucose uptake mediated by insulin [72]. This also increases the production of endogenous glucose. With the failure of glucose transporter type 4 (GLUT4), which is mainly located in adipocytes and muscle cells, glucose intake is reduced [75-79]. This causes an increase in circulating glucose that leads to increased insulin secretion. Consequently, glucose transporter types 1-3 (GLUT1-3), which are insulin-independent and found in neurons, renal cells, and erythrocytes, are exposed to a large amount of glucose that leads to glucotoxicity [75]. This results in prediabetes, a state characterized by glucose intolerance $[80,81]$. Additionally, the continuation of insulin resistance can lead the beta cells of the pancreas to get to a point where they can no longer provide the high amounts of insulin secreted before, leading to a drop in insulin secretion and further failure of glucose homeostasis [80,82].

Furthermore, there is an increase in the synthesis of triglycerides and very-low-density lipoproteins (VLDL) that contribute to the failure of the GLUT4 transporter [72,80]. According to the portal theory of MS, there are free fatty acids that are released from the accumulation of visceral fat. They enter the portal circulation and are transported to the liver where they remain as triglycerides $[83,84]$. This induces the release of VLDL by the liver and causes a state of hypertriglyceridemia [85]. These free fatty acids act on the phosphoinositide-3-kinase activity reducing its function and worsening insulin resistance [80]. These fats also contribute to the reduced production of insulin by the beta cells of the pancreas by exerting a lipotoxic effect on them [77]. Moreover, they contribute to endothelial effect by producing reactive oxygen species, along with the hyperinsulinemia state and the cytokines produced by the adipose tissue [83,86-88].

Regarding MS and inflammation, the state of inflammation in this syndrome is associated with damage of the gut barrier activity and bacterial exposure $[89,90]$. This endotoxemia may activate inflammatory pathways, along with further encroachment to various organs that can lead to an invasion of macrophages that help promote insulin resistance [91-93]. Additionally, it contributes to the accumulation of adiposity and insulin resistance [94].

There are several ways by which the microbiome may contribute to the development of obesity such as encouraging the accumulation of fat deposits and change in the locomotor activity setting off systemic inflammation [95]. Recently, a correlation has been reported between the high intake of fats and an inadequate function of the intestinal barrier that can ease the movement of intestinal luminal contents and bacterial lipopolysaccharide into the circulation $[94,96]$. These lipopolysaccharide chain cluster of differentiation 14 (CD14) receptors promote systemic inflammation [97].

\section{Current treatment protocols}

As mentioned above, MS is a multifaceted disease. Therefore, the management approach is targeted toward the prevention and reduction of cardiovascular risk factors such as obesity, type 2 diabetes mellitus, and hypertension [98]. Treatment goals are achieved through various modalities such as lifestyle modification and pharmaceutical management in high-risk individuals [99].

\section{Lifestyle Modifications}

To reduce the incidence of MS, early measures such as a low carbohydrate diet, increased physical activity, and controlled alcohol consumption are targeted, in particular, toward the younger generation [100,101]. Lifestyle changes have proven to be the more effective approach to reducing the incidence of MS and diabetes. In the Diabetes Prevention Study conducted over three years, a diabetic case reduction of $41 \%$ was seen with lifestyle changes compared to a $17 \%$ reduction only with metformin [102]. A diet commonly referred to as "the Mediterranean diet" is efficacious in preventing insulin resistance [103]. A Mediterranean diet consists of a wide range of fruits, vegetables, whole grains, and healthy fats such as seeds, nuts, and extra virgin olive oil. A limited quantity of fish, dairy, poultry, and red meat are also incorporated [104]. The rich plant sources consist of phenolic compounds that modify the insulin activity in the tissue and improve sensitivity $[103,105]$. Research-based recommendations for diet include $45 \%$ to $60 \%$ of carbohydrate intake (sourced from legumes and whole grains predominantly), 10\% to 20\% protein, and 10\% fatty acids. [106,107]. High fiber intake (40 g/day) also improves insulin sensitivity [107]. Although regular moderate physical exercise improves MS [108], the best results are observed when exercise is implemented in conjunction with an appropriate diet. A study conducted by Anderssen et al. compared the effects of combined interventions with those without dietary restrictions. They reported a 67\% and 24\% drop in MS incidence in the combined and isolated groups, respectively [109]. An intervention study, the Da Qing Trial, further supported the abovementioned findings. A more significant reduction of type 2 diabetes mellitus in the combined diet and exercise groups was observed compared to the isolated diet and activity groups (46\% vs. $43.8 \%$ vs. $41.1 \%$, respectively) [110].

\section{Pharmaceutical Management}

A well-established relationship exists between MS and type 2 diabetes mellitus [111], indicating that strict glycemic control can eliminate the risk factors of MS [112]. The two classes of drugs that predominantly affect insulin resistance are biguanides (metformin) and thiazolidinediones (glitazones) [113,114]. 
Metformin achieves the desired results through various mechanisms such as inhibiting glucose production in the liver [115], increasing glucose reuptake via insulin receptor activation, stimulating tyrosine kinase in the peripheral tissue [113,116], and lowering free fatty acid oxidation in adipose tissues [117]. A study on the mechanism of metformin by Hundal et al. demonstrated a $25 \%$ to $30 \%$ decrease in plasma glucose because of the actions of metformin on hepatocytes [115].

Glitazones improve metabolic control by binding with nuclear receptor PPAR- $\gamma$ and controlling glucose metabolism [118]. PPARs are ligand-inducible transcription factors that belong to the nuclear hormone receptors family. Three different isoforms of PPARs have been identified, namely, PPAR- $\alpha$, PPAR- $\beta / \delta$, and PPAR- $\gamma$. These are involved in adipogenesis, inflammation, lipid, and glucose metabolism [119,120].

Fenofibrate, the prototype of fibrate drugs, activates PPAR- $\alpha$ whereas bezafibrate is a pan-PPAR activator for all three PPAR isoforms. In a recent meta-analysis by Simental-Mendía et al., fibrate therapy significantly reduced fasting plasma glucose $(-0.28 \mathrm{mmol} / \mathrm{L})$, insulin levels $(-3.87 \mathrm{pmol} / \mathrm{L})$, and insulin resistance [Homeostasis Model of Assessment for Insulin Resistance (HOMA-IR) -1.09], with no effect on glycated hemoglobin (HbA1c) [121]. These effects are more pronounced with bezafibrate as it is a pan-PPAR activator.

All three drug classes have been hypothesized to have a protective effect on the cardiovascular system [122124]. However, these results are debatable and require further investigation.

Several other targeted therapies are implemented with the predominant metabolic risk factor in mind. In severe hypertension, newly introduced angiotensin receptor blockers (telmisartan and irbesartan) have shown promising results in comparison to other antihypertensive medications. These drugs behave similarly to glitazones and stimulate PPAR- $\gamma$, resulting in a reduction of blood pressure and an increase in insulin sensitivity [125].

In severe obesity (a BMI of at least $30 \mathrm{~kg} / \mathrm{m}^{2}$ ), where all other treatments have been unsatisfactory, pharmacological management can be considered [126]. The current treatment options include sibutramine and orlistat. A meta-analysis of randomized trials on sibutramine showed a $4.6 \%$ more weight loss than the placebo [127]. Increased insulin sensitivity and better glycemic control were also reported among diabetics [128]. In a diabetic study [129], a combined orlistat and diet regimen reduced MS by $35 \%$ versus $9 \%$ (diet alone). In addition to weight loss, orlistat also prevents type 2 diabetes mellitus and hyperglycemia [130].

Statins are primarily used as LDL-C-lowering agents in patients who meet the criteria for atherosclerotic cardiovascular disease (ASCVD) with MS. Its pleiotropic effects have proven to be significantly beneficial in patients with MS in reducing major coronary events $[2,98]$. MS has been associated with elevated C-reactive protein (CRP); statins lower CRP and reduce pro-inflammatory states, further exhibiting their prognostic value $[98,99]$. An interventional study in patients with MS focused on measuring effective reductions in cholesterol using rosuvastatin therapy (MERCURY Trial) found $10 \mathrm{mg}$ of rosuvastatin to be more promising compared to commonly used doses of other statins in achieving the target LDL-cholesterol level [98]. A similar study conducted by Grundy et al., the Comparative study with Rosuvastatin in Subjects with Metabolic Syndrome (COMETS), also demonstrated rosuvastatin to be an effective lipid-modifying agent in patients with MS. Moreover, recent studies have established that the combination of statins and fibrates or nicotinic acid is more efficient in reducing cardiovascular outcomes in addition to minimizing the risks of myopathy [99].

\section{Effectiveness of folate and vitamin B12 supplementation in insulin resistance and metabolic syndrome}

Folate supplementation has been established with protective studies in reducing insulin and HOMA-IR; however, inconsistent results have been reported regarding the reduction of fasting blood sugar and HbA1c levels [131]. The dosage of folate supplementation plays an important role in the reduction of insulin resistance [132]. The glycemic markers were effectively reduced with a folate dose greater than $5 \mathrm{mg} / \mathrm{day}$ [132]. A systematic review published by Xie et al. in 2016 showed that folic acid supplementation in maternal and prenatal animal groups decreased both insulin resistance and obesity significantly [133]. Further, folate prevented the decline in cognitive skills associated with metformin use in diabetes [134]. To support this, we reviewed a clinical study conducted by Porter et al. (2019) in a group of community-dwelling older adults and found that using fortified vitamin B12 foods improved the patient's cognitive status [134]. Scientific studies have evolved, paving the way for newer and promising treatments for insulin resistance. One such study used folate nanoparticles in rats to achieve an effective glycemic index [135]. It was demonstrated that using folate nanoparticles showed a five-fold enhancement in cellular uptake of insulin and that blood glucose levels were controlled effectively [135].

Furthermore, it was evident that dietary intake of folate and vitamin B12 had a positive impact on MS and reduced the risk of stroke in both men and women in the United States [136,137]. Spence et al. (2016) showed that supplementation with methylcobalamin minimized the incidence of stroke in persons with renal impairment and cyanocobalamin in patients without any renal impairment [138]. To highlight the 
relationship between low supplementation of folate and vitamin B12 and stroke, we reviewed a randomized controlled trial (RCT) conducted by Qin et al. (2020) in a double-blinded hypertensive population. The study revealed that people with low levels of folate and vitamin B12 were associated with an increased risk of ischemic stroke [139]. The duration of folate supplementation influenced the incidence of stroke by a reduction of $18 \%$ in people who consumed it for more than 36 months [140].

Another area of interest was to assess the effect of folate/vitamin B12 on cardiovascular diseases. Studies have highlighted plasma homocysteine levels to play an important role in the occurrence of myocardial infarction, and its levels were predominantly dependent on plasma folate values to a greater extent and vitamin B12 to a lesser extent [141]. This was further supported by a prospective study conducted by Stampfer et al. (1992) which assessed the risk of plasma homocysteine and cardiovascular diseases in U.S. physicians and found that the levels of homocysteine were higher in cases than in controls $(11.1 \pm 4.0$ standard deviation [SD] vs. $10.5 \pm 2.8 \mathrm{nmol} / \mathrm{mL}$ ) who later developed myocardial infarction, irrespective of other modifiable risk factors [142]. Furthermore, low vitamin B12 levels have been associated with the development of atherosclerosis, which is an important causative factor for cardiovascular diseases [143]. Moreover, because hyperhomocysteinemia has been linked with congenital heart disease malformation in children, periconceptional folate supplementation has proven to be a key factor in reducing congenital heart disease in children [144].

Along with cardiovascular diseases and stroke, another common condition associated with low folate/vitamin B12 levels is obesity [145]. A study by Kumar et al. (2012) included female Wistar rats which were deprived of a vitamin B12 diet and allowed to mate [146]. Biochemical and body parameters were measured in maternal rats before mating and in offspring at three, six, nine, and twelve months of age. It was demonstrated that the maternal rats suffered from increased body fat and altered lipid profile and the offspring had an increase in fatty acid synthase and higher plasma cortisol levels, thus paving the way to high visceral fat at three months and dyslipidemia at 12 months [146]. Therefore, it is recommended that pregnant females remain careful about their folate/vitamin B12 supplementation to prevent dyslipidemia and neural tube defects in the offspring [147]. It has been reported that both folate and vitamin B12 have a synergistic effect on the markers of obesity and lipid profile, such as the waist to hip length ratio, triglyceride level, and HDL-C level [148-150]. However, further clinical studies are required to warrant any unwanted side effects with the use of folate and vitamin B12 for insulin resistance and MS.

\section{Novel therapeutic approaches and targets}

MS is a constellation of disorders that usually involves the treatment of the individual disorder, along with dietary intervention and physical activity [98]. Due to a better understanding of the pathophysiology of MS, novel agents acting multiple targets and mechanisms are being developed [151].

Role of Selective Peroxisome Proliferator-Activated Receptor Modulators

Novel compounds, such as selective peroxisome proliferator-activated receptor modulators (SPPARMs), have more potent PPAR- $\alpha$ agonist activity. These are proven to have advantages in the treatment of insulin resistance and dyslipidemia. One such agent is pemafibrate. Pemafibrate is a novel, highly selective PPAR- $\alpha$ agonist approved for the treatment of hyperlipidemia in Japan. The recommended dosage of oral pemafibrate is $0.1 \mathrm{mg}$ twice daily, which can be adjusted to a maximum of $0.2 \mathrm{mg}$ twice daily [152]. It is more robust in reducing triglycerides and elevating HDL-C, thereby enhancing reverse cholesterol transport compared to fenofibrate [153]. Based on studies in mouse models, pemafibrate is more efficient in decreasing apolipoprotein B-48 (ApoB-48)-containing chylomicron remnants than those containing ApoB100. It is noteworthy that ApoB-48 is more atherogenic [154]. In an RCT conducted by Araki et al. on type 2 diabetes mellitus patients $(\mathrm{HbA} 1 \mathrm{c} \geqslant 6.2 \%$ ) with fasting triglycerides of $\geqslant 150 \mathrm{mg} / \mathrm{dL}$, not on statins, participants were randomly assigned to pemafibrate at doses of $0.2 \mathrm{mg} / \mathrm{day}, 0.4 \mathrm{mg} / \mathrm{day}$, and placebo. After 24 weeks of treatment, triglycerides declined by $45 \%$ in both doses; fasting triglycerides of $\leqslant 150 \mathrm{mg} / \mathrm{dL}$ were achieved in $70.9 \%$ and $81.5 \%$ of patients on $0.4 \mathrm{mg} /$ day and $0.2 \mathrm{mg} /$ day, respectively. No considerable changes in LDL-C were noted. However, an increment in HDL-C and ApoA-I was observed [155]. Among glycemic parameters, a significant decrease in HOMA-IR was noticed in the $0.2 \mathrm{mg} / \mathrm{day}$ pemafibrate group, while no significant changes were noted in other parameters. The most common adverse effects reported were increased serum creatinine and liver enzymes [155].

The most recent evidence regarding pemafibrate is yet to be obtained through a Pemafibrate to Reduce Cardiovascular OutcoMes by Reducing Triglycerides IN patiENts With diabeTes (PROMINENT) study which is a multicentre, randomized, phase 3 trial. The study recruited approximately 10,000 participants from 24 countries with type 2 diabetes mellitus, mild-to-moderate hypertriglyceridemia, and low HDL-C levels to either pemafibrate $(0.2 \mathrm{mg}$ twice daily) or matching placebo. The trial is currently ongoing with a mean follow-up period of 3.75 years [156]. Further studies are needed to determine the effect of pemafibrate in preventing cardiovascular disease.

Farnesoid X Receptor Agonists 
Farnesoid X receptor (FXR) belongs to the nuclear receptor family. Among bile acids, chenodeoxycholic acid is the most potent activator of FXR. These receptors are expressed in the liver, kidney, intestine, and adrenal glands [157]. Activation of FXR has been shown to increase insulin sensitivity and decrease triglycerides and free fatty acid levels. Recent data also suggest reduced endothelin levels, thereby playing a role in atherosclerosis [157]. Recently, obeticholic acid, an FXR agonist, has been approved for the treatment of primary biliary cholangitis. Newer FXR agonists such as nidufexor or tropifexor are under phase 2 clinical trials for the treatment of nonalcoholic fatty liver disease and non-alcoholic steatohepatitis, considered to be a hepatic manifestation of MS [158,159].

Asprosin and Asprosin Neutralizing Antibodies

Asprosin, a glucogenic adipokine, was discovered in 2016 in the study of the neonatal progeroid syndrome [160]. Sites of action include the liver and the brain. In the liver, it exerts a glucogenic effect through the cyclic adenosine monophosphate protein kinase A (cAMP-PKA)-dependent pathway [161]. It crosses the blood-brain barrier and stimulates appetite by activating orexigenic and inhibiting anorexigenic neurons in the arcuate nucleus of the hypothalamus. The levels have been found to be elevated in MS [161,162].

A preclinical study done on mice by Mishra et al. showed that a single dose of an anti-asprosin monoclonal antibody $(\mathrm{mAb})$ reduced food intake by an average of $1 \mathrm{~g} /$ day, resulting in decreased body weight. Other parameters such as triglycerides, blood glucose, and plasma insulin levels also decreased [162]. Anti-asprosin mAbs also exert action at the target level by inhibiting hepatic cAMP signaling and orexigenic neuron activity in the hypothalamus, in addition to neutralizing asprosin [161,162]. Further studies are required in humans to delineate efficacy and safety, and these preclinical study results offer better hope for the future.

\section{Peripheral Cannabinoid Receptor Antagonists}

Selective cannabinoid $(\mathrm{CB})$ receptor inhibition is a novel approach to treat MS and dyslipidemias. Cannabinoid receptors CB-1 and CB-2 are G protein-coupled receptors that activate $\mathrm{G}$ proteins (Gi/Go). CB-1 receptors are expressed in the brain and peripherally in the heart, liver, pancreas, and adipose tissue, whereas CB-2 receptors are found in immune cells [163]. Although the exact mechanism of CB receptor antagonists is not well understood, they have been found to modulate leptin levels. Another mechanism is through the activation of the peripheral sympathetic system [164].

The use of the CB-1 receptor antagonist dates back to 2006. Rimonabant, approved for the treatment of obesity, was withdrawn in 2008 because of an increase in depressive mood disorders associated with antagonism of central CB-1 receptors [165]. This leads to the development of compounds with limited central nervous system penetration and action on peripheral CB receptors. However, further studies are needed to demonstrate relevant metabolic endpoints [166]. Newer compounds of the CB receptor family which are in the preclinical phases of investigation are showing promising results $[167,168]$.

\section{Role of Fecal Microbiota Transplantation in Insulin Resistance}

The human gut microbiome harbors an estimated 10-100 trillion microorganisms. Gut microbial dysbiosis has been defined as alterations in diversity with more "inflammatory" microbes (i.e., Proteobacteria) and decreased short-chain fatty acid levels [169].

A recent study among 154 human twins shed light on the link between obesity and gut microbial diversity. Excess Bacteroidetes and deficient butyrate and propionate levels were noted in the gut microbiome of twins with obesity phenotype [170,171]. Two randomized control trials conducted by Kootte et al. and Vrieze et al. showed similar effects, such as improvement in insulin sensitivity and increased microbial diversity at six weeks after allogenic fecal microbiota transplantation (FMT) compared to autologous FMT [171,172]. Further, when metabolic parameters were measured at 18 weeks in the study by Kootte et al., no changes were observed. This study showed that the short-term effects of FMT are not maintained in the long term [171].

Although the role of FMT in insulin resistance is recognized, the role of FMT in hypertension is unclear. In studies on rat models for hypertension, a decreased microbiota diversity in the form of decreased Firmicutes/Bacteroidetes ratio was observed. Interestingly, the blood pressure in these rat models could be controlled by reversing the Firmicutes/Bacteroidetes ratio by utilizing antibiotics [173,174]. More controlled trials are needed to elucidate the potential benefit and sustainability of FMT in MS.

Adenosine Triphosphate Citrate Lyase Inhibitors

Adenosine triphosphate citrate lyase (ACLY) is a cytoplasmic enzyme that mediates the production of acetyl coenzyme A (acetyl-CoA) that acts as a substrate for the de novo synthesis of fatty acids and cholesterol [175]. 
Bempedoic acid, an ACLY inhibitor, is approved by the U.S. Food and Drug Administration (US FDA) for the treatment of heterozygous familial hypercholesterolemia (HeFH) and established ASCVD [175]. Bempedoic acid modulates adenosine monophosphate-activated protein kinase (AMPK) activation and decreases hepatic glucose production, an action similar to metformin [176]. In a randomized, 52-week, phase 3 trial, involving adults with ASCVD, HeFH, or both, bempedoic acid at a dose of $180 \mathrm{mg}$ once daily reduced the mean LDL-C level by $12.6 \%$ by week 52 [177]. The most frequent adverse effects observed included nasopharyngitis, muscle spasms, hyperuricemia, anemia, and elevated transaminases [177,178]. ACLY inhibitors can be used as the primary drug in patients who are intolerant to statins. Further studies are needed to evaluate the role of ACLY inhibitors in reducing inflammation, insulin resistance, and other components of MS.

\section{Central Leptin Gene Therapy}

The role of leptin resistance in MS has long been proven. Leptin, an adipogenic hormone, acts on the hypothalamus and increases satiety [179]. Burguera et al. postulated that "leptin resistance might be due to non-availability of leptin at hypothalamic target sites caused by either defective uptake across the bloodbrain barrier, or abnormal post-receptor signal transduction” [180].

Using recombinant adeno-associated virus vector for central leptin gene therapy in animal models showed decreased weight, insulin resistance, and increased thermogenesis [181]. Further long-term studies are required in humans as leptin gene therapy can offer a permanent solution to multiple components of MS.

\section{Conclusions}

This review aimed to understand the interactions between MS and vitamins B12 and folate and summarized the most relevant literature. To date, MS remains somewhat of an enigma as there is no consensus on how or why it develops. However, progress has been made on the therapeutic end, with a whole host of novel drugs being developed to treat the condition. Moreover, the impact of folate and vitamin B12 supplementation is a new frontier that is still relatively unexplored. We recommend further observational studies and RCTs that examine exactly how much vitamin supplementation affects each component of MS. Current literature suggests that these vitamins have a significant positive impact on MS, and they must be kept in mind while designing new treatment protocols in the future.

\section{Additional Information \\ Disclosures}

Conflicts of interest: In compliance with the ICMJE uniform disclosure form, all authors declare the following: Payment/services info: All authors have declared that no financial support was received from any organization for the submitted work. Financial relationships: All authors have declared that they have no financial relationships at present or within the previous three years with any organizations that might have an interest in the submitted work. Other relationships: All authors have declared that there are no other relationships or activities that could appear to have influenced the submitted work.

\section{References}

1. Grundy SM, Hansen B, Smith SC Jr, Cleeman JI, Kahn RA: Clinical management of metabolic syndrome: report of the American Heart Association/National Heart, Lung, and Blood Institute/American Diabetes Association conference on scientific issues related to management. Arterioscler Thromb Vasc Biol. 2004, 24:e19-24. 10.1161/01.ATV.0000112379.88385.67

2. Expert Panel on Detection, Evaluation, and Treatment of High Blood Cholesterol in Adults: Executive Summary of The Third Report of The National Cholesterol Education Program (NCEP) Expert Panel on Detection, Evaluation, and Treatment of High Blood Cholesterol in Adults (Adult Treatment Panel III). JAMA. 2001, 285:2486-97. 10.1001/jama.285.19.2486

3. Cornier MA, Dabelea D, Hernandez TL, et al.: The metabolic syndrome. Endocr Rev. 2008, 29:777-822. 10.1210/er.2008-0024

4. Kelly T, Yang W, Chen CS, Reynolds K, He J: Global burden of obesity in 2005 and projections to 2030 . Int J Obes (Lond). 2008, 32:1431-7. 10.1038/ijo.2008.102

5. Lyon P, Strippoli V, Fang B, Cimmino L: B vitamins and one-carbon metabolism: implications in human health and disease. Nutrients. 2020,12:2867. 10.3390/nu12092867

6. Mursleen MT, Riaz S: Implication of homocysteine in diabetes and impact of folate and vitamin B12 in diabetic population. Diabetes Metab Syndr. 2017, 11 Suppl 1:S141-6. 10.1016/j.dsx.2016.12.023

7. Škovierová H, Vidomanová E, Mahmood S, et al.: The molecular and cellular effect of homocysteine metabolism imbalance on human health. Int J Mol Sci. 2016, 17:1733. 10.3390/ijms17101733

8. Zendjabil M, Abbou O, Chellouai Z: [Association between metabolic syndrome and hyperhomocysteinemia in an Algerian population]. Ann Pharm Fr. 2017, 75:54-8. 10.1016/j.pharma.2016.05.001

9. Huang T, Ren J, Huang J, Li D: Association of homocysteine with type 2 diabetes: a meta-analysis implementing Mendelian randomization approach. BMC Genomics. 2013, 14:867. 10.1186/1471-2164-14867

10. Clarke R, Lewington S, Sherliker P, Armitage J: Effects of B-vitamins on plasma homocysteine concentrations and on risk of cardiovascular disease and dementia. Curr Opin Clin Nutr Metab Care. 2007, 
10:32-9. 10.1097/MCO.0b013e328011aa71

11. Kataria N, Yadav P, Kumar R, Kumar N, Singh M, Kant R, Kalyani V: Effect of vitamin B6, B9, and B12 supplementation on homocysteine level and cardiovascular outcomes in stroke patients: a meta-analysis of randomized controlled trials. Cureus. 2021, 13:e14958. 10.7759/cureus.14958

12. Satapathy S, Bandyopadhyay D, Patro BK, Khan S, Naik S: Folic acid and vitamin B12 supplementation in subjects with type 2 diabetes mellitus: a multi-arm randomized controlled clinical trial. Complement Ther Med. 2020, 53:102526. 10.1016/j.ctim.2020.102526

13. Gille D, Schmid A: Vitamin B12 in meat and dairy products . Nutr Rev. 2015, 73:106-15. 10.1093/nutrit/nuu011

14. Partearroyo T, Samaniego-Vaesken ML, Ruiz E, et al.: Dietary sources and intakes of folates and vitamin B12 in the Spanish population: findings from the ANIBES study. PLoS One. 2017, 12:e189230. 10.1371/journal.pone.0189230

15. González-Gross M, Benser J, Breidenassel C, et al.: Gender and age influence blood folate, vitamin B12, vitamin B6, and homocysteine levels in European adolescents: the Helena Study. Nutr Res. 2012, 32:817-26. 10.1016/j.nutres.2012.09.016

16. Roman Viñas B, Ribas Barba L, Ngo J, et al.: Projected prevalence of inadequate nutrient intakes in Europe . Ann Nutr Metab. 2011, 59:84-95. 10.1159/000332762

17. Sobiecki JG, Appleby PN, Bradbury KE, Key TJ: High compliance with dietary recommendations in a cohort of meat eaters, fish eaters, vegetarians, and vegans: results from the European Prospective Investigation into Cancer and Nutrition-Oxford study. Nutr Res. 2016, 36:464-77. 10.1016/j.nutres.2015.12.016

18. Gilsing AM, Crowe FL, Lloyd-Wright Z, Sanders TA, Appleby PN, Allen NE, Key TJ: Serum concentrations of vitamin B12 and folate in British male omnivores, vegetarians and vegans: results from a cross-sectional analysis of the EPIC-Oxford cohort study. Eur J Clin Nutr. 2010, 64:933-9. 10.1038/ejcn.2010.142

19. Watanabe F, Yabuta Y, Bito T, Teng F: Vitamin $B_{12}$-containing plant food sources for vegetarians . Nutrients. 2014, 6:1861-73. 10.3390/nu6051861

20. Sela I, Yaskolka Meir A, Brandis A, et al.: Wolffia globosa-Mankai plant-based protein contains bioactive vitamin B12 and is well absorbed in humans. Nutrients. 2020, 12:3067. 10.3390/nu12103067

21. Bito T, Teng F, Watanabe F: Bioactive compounds of edible purple laver Porphyra sp. (Nori) . J Agric Food Chem. 2017, 65:10685-92. 10.1021/acs.jafc.7b04688

22. Nakos M, Pepelanova I, Beutel S, Krings U, Berger RG, Scheper T: Isolation and analysis of vitamin B12 from plant samples. Food Chem. 2017, 216:301-8. 10.1016/j.foodchem.2016.08.037

23. Naik S, Bhide V, Babhulkar A, Mahalle N, Parab S, Thakre R, Kulkarni M: Daily milk intake improves vitamin B-12 status in young vegetarian Indians: an intervention trial. Nutr J. 2013, 12:136. 10.1186/1475-2891-12136

24. Altic L, McNulty H, Hoey L, McAnena L, Pentieva K: Validation of folate-enriched eggs as a functional food for improving folate intake in consumers. Nutrients. 2016, 8:777. 10.3390/nu8120777

25. Duplessis M, Pellerin D, Robichaud R, Fadul-Pacheco L, Girard CL: Impact of diet management and composition on vitamin B12 concentration in milk of Holstein cows. Animal. 2019, 13:2101-9. 10.1017/S1751731119000211

26. Duplessis M, Ritz KE, Socha MT, Girard CL: Cross-sectional study of the effect of diet composition on plasma folate and vitamin B12 concentrations in Holstein cows in the United States and Canada. J Dairy Sci. 2020, 103:2883-95. 10.3168/jds.2019-17657

27. Xu NN, Yang DT, Zhang BX, Liu JX, Ye JA, Ren DX: Short communication: influence of intramuscular injection of vitamin B12 in early-lactation dairy cows on Mozzarella cheese quality and vitamin B12 stability. J Dairy Sci. 2020, 103:9835-40. 10.3168/jds.2020-18568

28. Dror DK, Allen LH: Vitamin B-12 in human milk: a systematic review . Adv Nutr. 2018, 9:358S-66S. 10.1093/advances/nmx019

29. Naderi N, House JD: Recent developments in folate nutrition. Adv Food Nutr Res. 2018, 83:195-213. 10.1016/bs.afnr.2017.12.006

30. Modupe O, Krishnaswamy K, Diosady LL: Technology for triple fortification of salt with folic acid, iron, and iodine. J Food Sci. 2019, 84:2499-506. 10.1111/1750-3841.14730

31. Modupe O, Diosady LL: Quadruple fortification of salt for the delivery of iron, iodine, folic acid, and vitamin B12 to vulnerable populations. J Food Eng. 2021, 300:110525. 10.1016/j.jfoodeng.2021.110525

32. Murugu DK, Onyango AN, Ndiritu AK, Osuga IM, Xavier C, Nakimbugwe D, Tanga CM: From farm to fork: crickets as alternative source of protein, minerals, and vitamins. Front Nutr. 2021, 8:704002. 10.3389/fnut.2021.704002

33. Mahara FA, Nuraida L, Lioe HN: Folate in milk fermented by lactic acid bacteria from different food sources . Prev Nutr Food Sci. 2021, 26:230-40. 10.3746/pnf.2021.26.2.230

34. Vora RM, Alappattu MJ, Zarkar AD, Soni MS, Karmarkar SJ, Antony AC: Potential for elimination of folate and vitamin B12 deficiency in India using vitamin-fortified tea: a preliminary study. BMJ Nutr Prev Health. 2021, 4:293-306. 10.1136/bmjnph-2020-000209

35. Bito T, Okumura E, Fujishima M, Watanabe F: Potential of chlorella as a dietary supplement to promote human health. Nutrients. 2020, 12:2524. 10.3390/nu12092524

36. Fang H, Kang J, Zhang D: Microbial production of vitamin B12: a review and future perspectives . Microb Cell Fact. 2017, 16:15. 10.1186/s12934-017-0631-y

37. Froese DS, Fowler B, Baumgartner MR: Vitamin B12, folate, and the methionine remethylation cyclebiochemistry, pathways, and regulation. J Inherit Metab Dis. 2019, 42:673-85. 10.1002/jimd.12009

38. Wright AJ, Dainty JR, Finglas PM: Folic acid metabolism in human subjects revisited: potential implications for proposed mandatory folic acid fortification in the UK. Br J Nutr. 2007, 98:667-75. 10.1017/S0007114507777140

39. Visentin M, Diop-Bove N, Zhao R, Goldman ID: The intestinal absorption of folates . Annu Rev Physiol. 2014, 76:251-74. 10.1146/annurev-physiol-020911-153251

40. Fan J, Ye J, Kamphorst JJ, Shlomi T, Thompson CB, Rabinowitz JD: Quantitative flux analysis reveals folatedependent NADPH production. Nature. 2014, 510:298-302. 10.1038/nature13236 
41. Finer S, Saravanan P, Hitman G, Yajnik C: The role of the one-carbon cycle in the developmental origins of type 2 diabetes and obesity. Diabet Med. 2014, 31:263-72. 10.1111/dme.12390

42. Paul L, Selhub J: Interaction between excess folate and low vitamin B12 status. Mol Aspects Med. 2017, 53:43-7. 10.1016/j.mam.2016.11.004

43. Donaldson RM Jr: Small bowel bacterial overgrowth. Adv Intern Med. 1970, 16:191-212.

44. Allen LH: Causes of vitamin B12 and folate deficiency. Food Nutr Bull. 2008, 29:S20-34; discussion S35-7. $10.1177 / 156482650802925105$

45. Steinberg WM, King CE, Toskes PP: Malabsorption of protein-bound cobalamin but not unbound cobalamin during cimetidine administration. Dig Dis Sci. 1980, 25:188-91. 10.1007/BF01308137

46. Binder HJ, Donaldson RM Jr: Effect of cimetidine on intrinsic factor and pepsin secretion in man . Gastroenterology. 1978, 74:371-5. 10.1016/0016-5085(78)90764-3

47. Vatn MH, Schrumpf E, Talseth T: Effect of cimetidine on intrinsic factor secretion stimulated by different doses of pentagastrin in patients with impaired renal function. Scand J Gastroenterol. 1983, 18:1109-14. $10.3109 / 00365528309181849$

48. Streeter AM, Goulston KJ, Bathur FA, Hilmer RS, Crane GG, Pheils MT: Cimetidine and malabsorption of cobalamin. Dig Dis Sci. 1982, 27:13-6. 10.1007/BF01308115

49. Marcuard SP, Albernaz L, Khazanie PG: Omeprazole therapy causes malabsorption of cyanocobalamin (vitamin B12). Ann Intern Med. 1994, 120:211-5. 10.7326/0003-4819-120-3-199402010-00006

50. Li N, Sood GK, Seetharam S, Seetharam B: Polymorphism of human transcobalamin II: substitution of proline and/or glutamine residues by arginine. Biochim Biophys Acta. 1994, 1219:515-20. 10.1016/01674781(94)90079-5

51. McKillop DJ, Pentieva K, Daly D, et al.: The effect of different cooking methods on folate retention in various foods that are amongst the major contributors to folate intake in the UK diet. Br J Nutr. 2002, 88:681-8. 10.1079/BJN2002733

52. Castenmiller JJ, van de Poll CJ, West CE, Brouwer IA, Thomas CM, van Dusseldorp M: Bioavailability of folate from processed spinach in humans. Effect of food matrix and interaction with carotenoids. Ann Nutr Metab. 2000, 44:163-9. 10.1159/000012840

53. Malin JD: Total folate activity in Brussels sprouts: the effects of storage, processing, cooking and ascorbic acid content. Int J Food Sci Technol. 2007, 12:623-32. 10.1111/j.1365-2621.1977.tb00149.x

54. Russell RM, Rosenberg IH, Wilson PD, et al.: Increased urinary excretion and prolonged turnover time of folic acid during ethanol ingestion. Am J Clin Nutr. 1983, 38:64-70. 10.1093/ajcn/38.1.64

55. Halsted CH, Villanueva JA, Devlin AM, et al.: Folate deficiency disturbs hepatic methionine metabolism and promotes liver injury in the ethanol-fed micropig. Proc Natl Acad Sci U S A. 2002, 99:10072-7. 10.1073/pnas. 112336399

56. Molloy AM, Daly S, Mills JL, et al.: Thermolabile variant of 5,10-methylenetetrahydrofolate reductase associated with low red-cell folates: implications for folate intake recommendations. Lancet. 1997, 349:1591-3. 10.1016/S0140-6736(96)12049-3

57. Samson SL, Garber AJ: Metabolic syndrome. Endocrinol Metab Clin North Am. 2014, 43:1-23. 10.1016/j.ecl.2013.09.009

58. Kahn SE, Hull RL, Utzschneider KM: Mechanisms linking obesity to insulin resistance and type 2 diabetes. Nature. 2006, 444:840-6. 10.1038/nature05482

59. Gallagher EJ, Leroith D, Karnieli E: The metabolic syndrome--from insulin resistance to obesity and diabetes. Med Clin North Am. 2011, 95:855-73. 10.1016/j.mcna.2011.06.001

60. Kahn BB, Flier JS: Obesity and insulin resistance. J Clin Invest. 2000, 106:473-81. 10.1172/JCI10842

61. Ogden CL, Carroll MD, Kit BK, Flegal KM: Prevalence of obesity and trends in body mass index among US children and adolescents, 1999-2010. JAMA. 2012, 307:483-90. 10.1001/jama.2012.40

62. Ng M, Fleming T, Robinson M, et al.: Global, regional, and national prevalence of overweight and obesity in children and adults during 1980-2013: a systematic analysis for the Global Burden of Disease Study 2013. Lancet. 2014, 384:766-81. 10.1016/S0140-6736(14)60460-8

63. World Health Organization. Obesity and overweight. (2015). Accessed: July 28, 2021: https://www.who.int/en/news-room/fact-sheets/detail/obesity-and-overweight.

64. World Health Organization. Global report on diabetes . (2016). Accessed: July 28, 2021: https://www.who.int/publications/i/item/9789241565257.

65. Razmpoosh E, Javadi A, Ejtahed HS, Mirmiran P, Javadi M, Yousefinejad A: The effect of probiotic supplementation on glycemic control and lipid profile in patients with type 2 diabetes: a randomized placebo controlled trial. Diabetes Metab Syndr. 2019, 13:175-82. 10.1016/j.dsx.2018.08.008

66. Palomba S, Santagni S, Falbo A, La Sala GB: Complications and challenges associated with polycystic ovary syndrome: current perspectives. Int J Womens Health. 2015, 7:745-63. 10.2147/IJWH.S70314

67. DeUgarte CM, Bartolucci AA, Azziz R: Prevalence of insulin resistance in the polycystic ovary syndrome using the homeostasis model assessment. Fertil Steril. 2005, 83:1454-60. 10.1016/j.fertnstert.2004.11.070

68. Alexander CM, Landsman PB, Teutsch SM, Haffner SM: NCEP-defined metabolic syndrome, diabetes, and prevalence of coronary heart disease among NHANES III participants age 50 years and older. Diabetes. 2003, 52:1210-4. 10.2337/diabetes.52.5.1210

69. McCracken E, Monaghan M, Sreenivasan S: Pathophysiology of the metabolic syndrome. Clin Dermatol. 2018, 36:14-20. 10.1016/j.clindermatol.2017.09.004

70. Wallace TM, Matthews DR: The assessment of insulin resistance in man . Diabet Med. 2002, 19:527-34. 10.1046/j.1464-5491.2002.00745.x

71. Eckel RH, Alberti KG, Grundy SM, Zimmet PZ: The metabolic syndrome. Lancet. 2010, 375:181-3. 10.1016/S0140-6736(09)61794-3

72. Matsuzawa Y, Funahashi T, Nakamura T: The concept of metabolic syndrome: contribution of visceral fat accumulation and its molecular mechanism. J Atheroscler Thromb. 2011, 18:629-39. 10.5551/jat.7922

73. Lusis AJ, Attie AD, Reue K: Metabolic syndrome: from epidemiology to systems biology . Nat Rev Genet. 2008, 9:819-30. 10.1038/nrg2468

74. Loos RJ, Rankinen T: Gene-diet interactions on body weight changes . J Am Diet Assoc. 2005, 105:S29-34. 
10.1016/j.jada.2005.02.015

75. Langouche L, Van den Berghe G: Glucose metabolism and insulin therapy . Crit Care Clin. 2006, 22:119-29, vii. $10.1016 /$ j.ccc. 2005.09 .005

76. Thorell A, Nygren J, Ljungqvist O: Insulin resistance: a marker of surgical stress . Curr Opin Clin Nutr Metab Care. 1999, 2:69-78. 10.1097/00075197-199901000-00012

77. Tooke JE, Hannemann MM: Adverse endothelial function and the insulin resistance syndrome. J Intern Med. 2000, 247:425-31. 10.1046/j.1365-2796.2000.00671.x

78. Shulman GI: Cellular mechanisms of insulin resistance. J Clin Invest. 2000, 106:171-6. 10.1172/JCI10583

79. Thorell A, Nygren J, Hirshman MF, et al.: Surgery-induced insulin resistance in human patients: relation to glucose transport and utilization. Am J Physiol. 1999, 276:E754-61. 10.1152/ajpendo.1999.276.4.E754

80. Avramoglu RK, Basciano H, Adeli K: Lipid and lipoprotein dysregulation in insulin resistant states . Clin Chim Acta. 2006, 368:1-19. 10.1016/j.cca.2005.12.026

81. Genuth S, Alberti KG, Bennett P, et al.: Follow-up report on the diagnosis of diabetes mellitus . Diabetes Care. 2003, 26:3160-7. 10.2337/diacare.26.11.3160

82. Barrett KE, Barman SM, Brooks HL, Yuan JX: Ganong's review of medical physiology. McGraw-Hill Education, Singapore; 2019.

83. Bergman RN, Kim SP, Hsu IR, et al.: Abdominal obesity: role in the pathophysiology of metabolic disease and cardiovascular risk. Am J Med. 2007, 120:S3-8; discussion S29-32. 10.1016/j.amjmed.2006.11.012

84. Klop B, Elte JW, Cabezas MC: Dyslipidemia in obesity: mechanisms and potential targets . Nutrients. 2013, 5:1218-40. 10.3390/nu5041218

85. Nikolic D, Katsiki N, Montalto G, Isenovic ER, Mikhailidis DP, Rizzo M: Lipoprotein subfractions in metabolic syndrome and obesity: clinical significance and therapeutic approaches. Nutrients. 2013, 5:92848. 10.3390/nu5030928

86. Gupta A, Gupta V: Metabolic syndrome: what are the risks for humans? . Biosci Trends. 2010, 4:204-12.

87. Reaven GM: Relationships among insulin resistance, type 2 diabetes, essential hypertension, and cardiovascular disease: similarities and differences. J Clin Hypertens (Greenwich). 2011, 13:238-43. 10.1111/j.1751-7176.2011.00439.x

88. Andreassi MG: Metabolic syndrome, diabetes and atherosclerosis: influence of gene-environment interaction. Mutat Res. 2009, 667:35-43. 10.1016/j.mrfmmm.2008.10.018

89. Piya MK, Harte AL, McTernan PG: Metabolic endotoxaemia: is it more than just a gut feeling? . Curr Opin Lipidol. 2013, 24:78-85. 10.1097/MOL.0b013e32835b4431

90. Bester I, Soma P, Kell DB, Pretorius E: Viscoelastic and ultrastructural characteristics of whole blood and plasma in Alzheimer-type dementia, and the possible role of bacterial lipopolysaccharides (LPS). Oncotarget. 2015, 6:35284-303. 10.18632/oncotarget.6074

91. Shoelson SE, Lee J, Goldfine AB: Inflammation and insulin resistance. J Clin Invest. 2006, 116:1793-801. 10.1172//CI29069

92. Koren O, Spor A, Felin J, et al.: Human oral, gut, and plaque microbiota in patients with atherosclerosis . Proc Natl Acad Sci U S A. 2011, 108 Suppl 1:4592-8. 10.1073/pnas.1011383107

93. Zulian A, Cancello R, Ruocco C, et al.: Differences in visceral fat and fat bacterial colonization between ulcerative colitis and Crohn's disease. An in vivo and in vitro study. PLoS One. 2013, 8:e78495. 10.1371/journal.pone.0078495

94. Cani PD, Amar J, Iglesias MA, et al.: Metabolic endotoxemia initiates obesity and insulin resistance. Diabetes. 2007, 56:1761-72. 10.2337/db06-1491

95. Tsai F, Coyle WJ: The microbiome and obesity: is obesity linked to our gut flora? . Curr Gastroenterol Rep. 2009, 11:307-13. 10.1007/s11894-009-0045-z

96. Cani PD, Neyrinck AM, Maton N, Delzenne NM: Oligofructose promotes satiety in rats fed a high-fat diet: involvement of glucagon-like peptide-1. Obes Res. 2005, 13:1000-7. 10.1038/oby.2005.117

97. DiBaise JK, Zhang H, Crowell MD, Krajmalnik-Brown R, Decker GA, Rittmann BE: Gut microbiota and its possible relationship with obesity. Mayo Clin Proc. 2008, 83:460-9. 10.4065/83.4.460

98. Bianchi C, Penno G, Romero F, Del Prato S, Miccoli R: Treating the metabolic syndrome. Expert Rev Cardiovasc Ther. 2007, 5:491-506. 10.1586/14779072.5.3.491

99. Grundy SM, Cleeman JI, Daniels SR, et al.: Diagnosis and management of the metabolic syndrome: an American Heart Association/National Heart, Lung, and Blood Institute Scientific Statement. Circulation. 2005, 112:2735-52. 10.1161/CIRCULATIONAHA.105.169404

100. Zhu S, St-Onge MP, Heshka S, Heymsfield SB: Lifestyle behaviors associated with lower risk of having the metabolic syndrome. Metabolism. 2004, 53:1503-11. 10.1016/j.metabol.2004.04.017

101. Ferreira I, Twisk JW, van Mechelen W, Kemper HC, Stehouwer CD: Development of fatness, fitness, and lifestyle from adolescence to the age of 36 years: determinants of the metabolic syndrome in young adults: the Amsterdam growth and health longitudinal study. Arch Intern Med. 2005, 165:42-8. 10.1001/archinte.165.1.42

102. Orchard TJ, Temprosa M, Goldberg R, Haffner S, Ratner R, Marcovina S, Fowler S: The effect of metformin and intensive lifestyle intervention on the metabolic syndrome: the Diabetes Prevention Program randomized trial. Ann Intern Med. 2005, 142:611-9. 10.7326/0003-4819-142-8-200504190-00009

103. Galan-Lopez P, Sanchez-Oliver AJ, Pihu M, Gísladóttír T, Domínguez R, Ries F: Association between adherence to the Mediterranean diet and physical fitness with body composition parameters in 1717 European adolescents: the AdolesHealth Study. Nutrients. 2019, 12:77. 10.3390/nu12010077

104. Davis C, Bryan J, Hodgson J, Murphy K: Definition of the Mediterranean diet; a literature review . Nutrients. 2015, 7:9139-53. 10.3390/nu7115459

105. Ylönen K, Saloranta C, Kronberg-Kippilä C, Groop L, Aro A, Virtanen SM: Associations of dietary fiber with glucose metabolism in nondiabetic relatives of subjects with type 2 diabetes: the Botnia Dietary Study. Diabetes Care. 2003, 26:1979-85. 10.2337/diacare.26.7.1979

106. Mann JI: Nutrition recommendations for the treatment and prevention of type 2 diabetes and the metabolic syndrome: an evidenced-based review. Nutr Rev. 2006, 64:422-7. 10.1111/j.1753-4887.2006.tb00227.x

107. Schulze MB, Liu S, Rimm EB, Manson JE, Willett WC, Hu FB: Glycemic index, glycemic load, and dietary 
fiber intake and incidence of type 2 diabetes in younger and middle-aged women. Am J Clin Nutr. 2004, 80:348-56. 10.1093/ajcn/80.2.348

108. Katzmarzyk PT, Leon AS, Wilmore JH, Skinner JS, Rao DC, Rankinen T, Bouchard C: Targeting the metabolic syndrome with exercise: evidence from the HERITAGE Family Study. Med Sci Sports Exerc. 2003, 35:1703-9. 10.1249/01.MSS.0000089337.73244.9B

109. Anderssen SA, Carroll S, Urdal P, Holme I: Combined diet and exercise intervention reverses the metabolic syndrome in middle-aged males: results from the Oslo Diet and Exercise Study. Scand J Med Sci Sports. 2007, $17: 687-95.10 .1111 /$ j.1600-0838.2006.00631.x

110. Pan XR, Li GW, Hu YH, et al.: Effects of diet and exercise in preventing NIDDM in people with impaired glucose tolerance. The Da Qing IGT and Diabetes Study. Diabetes Care. 1997, 20:537-44. 10.2337/diacare.20.4.537

111. Ford ES, Giles WH, Mokdad AH: Increasing prevalence of the metabolic syndrome among U.S. Adults. Diabetes Care. 2004, 27:2444-9. 10.2337/diacare.27.10.2444

112. Anioke IC, Ezedigboh AN, Dozie-Nwakile OC, Chukwu IJ, Kalu PN: Predictors of poor glycemic control in adult with type 2 diabetes in South-Eastern Nigeria. Afr Health Sci. 2019, 19:2819-28. 10.4314/ahs.v19i4.3

113. Stith BJ, Woronoff K, Wiernsperger N: Stimulation of the intracellular portion of the human insulin receptor by the antidiabetic drug metformin. Biochem Pharmacol. 1998, 55:533-6. 10.1016/s0006-2952(97)00540-6

114. Saltiel AR, Olefsky JM: Thiazolidinediones in the treatment of insulin resistance and type II diabetes . Diabetes. 1996, 45:1661-9. 10.2337/diab.45.12.1661

115. Hundal RS, Krssak M, Dufour S, et al.: Mechanism by which metformin reduces glucose production in type 2 diabetes. Diabetes. 2000, 49:2063-9. 10.2337/diabetes.49.12.2063

116. Gunton JE, Delhanty PJ, Takahashi S, Baxter RC: Metformin rapidly increases insulin receptor activation in human liver and signals preferentially through insulin-receptor substrate-2. J Clin Endocrinol Metab. 2003, 88:1323-32. 10.1210/jc.2002-021394

117. Riccio A, Del Prato S, Vigili de Kreutzenberg S, Tiengo A: Glucose and lipid metabolism in non-insulindependent diabetes. Effect of metformin. Diabete Metab. 1991, 17:180-4.

118. Mudaliar S, Henry RR: New oral therapies for type 2 diabetes mellitus: the glitazones or insulin sensitizers . Annu Rev Med. 2001, 52:239-57. 10.1146/annurev.med.52.1.239

119. Dubois V, Eeckhoute J, Lefebvre P, Staels B: Distinct but complementary contributions of PPAR isotypes to energy homeostasis. J Clin Invest. 2017, 127:1202-14. 10.1172/JCI88894

120. Botta M, Audano M, Sahebkar A, Sirtori CR, Mitro N, Ruscica M: PPAR agonists and metabolic syndrome: an established role?. Int J Mol Sci. 2018, 19:E1197. 10.3390/ijms19041197

121. Simental-Mendía LE, Simental-Mendía M, Sánchez-García A, Banach M, Atkin SL, Gotto AM Jr, Sahebkar A: Effect of fibrates on glycemic parameters: a systematic review and meta-analysis of randomized placebocontrolled trials. Pharmacol Res. 2018, 132:232-41. 10.1016/j.phrs.2017.12.030

122. Wiernsperger NF: Metformin: intrinsic vasculoprotective properties. Diabetes Technol Ther. 2000, 2:259-72. $10.1089 / 15209150050025230$

123. Sidhu JS, Cowan D, Kaski JC: The effects of rosiglitazone, a peroxisome proliferator-activated receptorgamma agonist, on markers of endothelial cell activation, C-reactive protein, and fibrinogen levels in nondiabetic coronary artery disease patients. J Am Coll Cardiol. 2003, 42:1757-63. 10.1016/j.jacc.2003.04.001

124. Elam MB, Ginsberg HN, Lovato LC, et al.: Association of fenofibrate therapy with long-term cardiovascular risk in statin-treated patients with type 2 diabetes. JAMA Cardiol. 2017, 2:370-80. 10.1001/jamacardio.2016.4828

125. Pershadsingh HA: Treating the metabolic syndrome using angiotensin receptor antagonists that selectively modulate peroxisome proliferator-activated receptor-gamma. Int J Biochem Cell Biol. 2006, 38:766-81. 10.1016/j.biocel.2005.08.006

126. Blackwell J: Identification, evaluation, and treatment of overweight and obese adults . J Am Acad Nurse Pract. 2002, 14:196-8. 10.1111/j.1745-7599.2002.tb00113.x

127. Padwal R, Li SK, Lau DC: Long-term pharmacotherapy for overweight and obesity: a systematic review and meta-analysis of randomized controlled trials. Int J Obes Relat Metab Disord. 2003, 27:1437-46. 10.1038/sj.ijo.0802475

128. McNulty SJ, Ur E, Williams G: A randomized trial of sibutramine in the management of obese type 2 diabetic patients treated with metformin. Diabetes Care. 2003, 26:125-31. 10.2337/diacare.26.1.125

129. Didangelos TP, Thanopoulou AK, Bousboulas SH, et al.: The ORLIstat and CArdiovascular risk profile in patients with metabolic syndrome and type 2 DIAbetes (ORLICARDIA) Study. Curr Med Res Opin. 2004, 20:1393-401. 10.1185/030079904125004466

130. Thearle M, Aronne LJ: Obesity and pharmacologic therapy. Endocrinol Metab Clin North Am. 2003, 32:100524. 10.1016/s0889-8529(03)00066-5

131. Akbari M, Tabrizi R, Lankarani KB, et al.: The effects of folate supplementation on diabetes biomarkers among patients with metabolic diseases: a systematic review and meta-analysis of randomized controlled trials. Horm Metab Res. 2018, 50:93-105. 10.1055/s-0043-125148

132. Asbaghi O, Ashtary-Larky D, Bagheri R, et al.: Folic acid supplementation improves glycemic control for diabetes prevention and management: a systematic review and dose-response meta-analysis of randomized controlled trials. Nutrients. 2021, 13:2355. 10.3390/nu13072355

133. Xie RH, Liu YJ, Retnakaran R, et al.: Maternal folate status and obesity/insulin resistance in the offspring: a systematic review. Int J Obes (Lond). 2016, 40:1-9. 10.1038/ijo.2015.189

134. Porter KM, Ward M, Hughes CF, et al.: Hyperglycemia and metformin use are associated with B vitamin deficiency and cognitive dysfunction in older adults. J Clin Endocrinol Metab. 2019, 104:4837-47. 10.1210/jc.2018-01791

135. El Leithy ES, Abdel-Bar HM, Ali RA: Folate-chitosan nanoparticles triggered insulin cellular uptake and improved in vivo hypoglycemic activity. Int J Pharm. 2019, 571:118708. 10.1016/j.ijpharm.2019.118708

136. Setola E, Monti LD, Galluccio E, et al.: Insulin resistance and endothelial function are improved after folate and vitamin B12 therapy in patients with metabolic syndrome: relationship between homocysteine levels and hyperinsulinemia. Eur J Endocrinol. 2004, 151:483-9. 10.1530/eje.0.1510483 
137. Bazzano LA, He J, Ogden LG, Loria C, Vupputuri S, Myers L, Whelton PK: Dietary intake of folate and risk of stroke in US men and women: NHANES I Epidemiologic Follow-up Study. National Health and Nutrition Examination Survey. Stroke. 2002, 33:1183-8. 10.1161/01.str.0000014607.90464.88

138. Spence JD: Metabolic vitamin B12 deficiency: a missed opportunity to prevent dementia and stroke . Nutr Res. 2016, 36:109-16. 10.1016/j.nutres.2015.10.003

139. Qin X, Spence JD, Li J, et al.: Interaction of serum vitamin B12 and folate with MTHFR genotypes on risk of ischemic stroke. Neurology. 2020, 94:e1126-36. 10.1212/WNL.00000000000008932

140. Wang X, Qin X, Demirtas H, et al.: Efficacy of folic acid supplementation in stroke prevention: a metaanalysis. Lancet. 2007, 369:1876-82. 10.1016/S0140-6736(07)60854-X

141. Verhoef P, Stampfer MJ, Buring JE, et al.: Homocysteine metabolism and risk of myocardial infarction: relation with vitamins B6, B12, and folate. Am J Epidemiol. 1996, 143:845-59. 10.1093/oxfordjournals.aje.a008828

142. Stampfer MJ, Malinow MR, Willett WC, et al.: A prospective study of plasma homocyst(e)ine and risk of myocardial infarction in US physicians. JAMA. 1992, 268:877-81. 10.1001/jama.1992.03490070059042

143. Siri PW, Verhoef P, Kok FJ: Vitamins B6, B12, and folate: association with plasma total homocysteine and risk of coronary atherosclerosis. J Am Coll Nutr. 1998, 17:435-41. 10.1080/07315724.1998.10718790

144. Elizabeth KE, Praveen SL, Preethi NR, Jissa VT, Pillai MR: Folate, vitamin B12, homocysteine and polymorphisms in folate metabolizing genes in children with congenital heart disease and their mothers. Eur J Clin Nutr. 2017, 71:1437-41. 10.1038/ejcn.2017.135

145. Thomas-Valdés S, Tostes MD, Anunciação PC, da Silva BP, Sant'Ana HM: Association between vitamin deficiency and metabolic disorders related to obesity. Crit Rev Food Sci Nutr. 2017, 57:3332-43. 10.1080/10408398.2015.1117413

146. Kumar KA, Lalitha A, Pavithra D, et al.: Maternal dietary folate and/or vitamin B12 restrictions alter body composition (adiposity) and lipid metabolism in Wistar rat offspring. J Nutr Biochem. 2013, 24:25-31. 10.1016/j.jnutbio.2012.01.004

147. O'Malley EG, Reynolds CM, Cawley S, Woodside JV, Molloy AM, Turner MJ: Folate and vitamin B12 levels in early pregnancy and maternal obesity. Eur J Obstet Gynecol Reprod Biol. 2018, 231:80-4.

10.1016/j.ejogrb.2018.10.001

148. Daviddi G, Ricci MA, De Vuono S, Gentili A, Boni M, Lupattelli G: Folate and vitamin B12 in morbid obesity: the influence of folate on anti-atherogenic lipid profile. Int J Vitam Nutr Res. 2020, 90:295-301. 10.1024/0300-9831/a000538

149. Paratthakonkun C, Kaewprasert S, Arthan D, et al.: Associations among serum folate, waist-to-hip ratio, lipid profile, and eating habits with homocysteine in an elderly Thai population. Int J Vitam Nutr Res. 2019, 89:246-54. 10.1024/0300-9831/a000402

150. Lima RP, do Nascimento RA, Luna RC, et al.: Effect of a diet containing folate and hazelnut oil capsule on the methylation level of the ADRB3 gene, lipid profile and oxidative stress in overweight or obese women. Clin Epigenetics. 2017, 9:110. 10.1186/s13148-017-0407-6

151. Rollason V, Vogt N: Reduction of polypharmacy in the elderly: a systematic review of the role of the pharmacist. Drugs Aging. 2003, 20:817-32. 10.2165/00002512-200320110-00003

152. Blair HA: Pemafibrate: first global approval. Drugs. 2017, 77:1805-10. 10.1007/s40265-017-0818-X

153. Hennuyer N, Duplan I, Paquet C, et al.: The novel selective PPAR $\alpha$ modulator (SPPARM $\alpha$ ) pemafibrate improves dyslipidemia, enhances reverse cholesterol transport and decreases inflammation and atherosclerosis. Atherosclerosis. 2016, 249:200-8. 10.1016/j.atherosclerosis.2016.03.003

154. Sairyo M, Kobayashi T, Masuda D, et al.: A novel selective PPAR $\alpha$ modulator (SPPARM $\alpha$ ), K- 877 (pemafibrate), attenuates postprandial hypertriglyceridemia in mice. J Atheroscler Thromb. 2018, 25:14252. 10.5551/jat.39693

155. Araki E, Yamashita S, Arai H, et al.: Effects of pemafibrate, a novel selective PPAR $\alpha$ modulator, on lipid and glucose metabolism in patients with type 2 diabetes and hypertriglyceridemia: a randomized, double-blind, placebo-controlled, phase 3 trial. Diabetes Care. 2018, 41:538-46. 10.2337/dc17-1589

156. Pradhan AD, Paynter NP, Everett BM, et al.: Rationale and design of the Pemafibrate to Reduce Cardiovascular Outcomes by Reducing Triglycerides in Patients with Diabetes (PROMINENT) study. Am Heart J. 2018, 206:80-93. 10.1016/j.ahj.2018.09.011

157. Cariou B, Staels B: FXR: a promising target for the metabolic syndrome? . Trends Pharmacol Sci. 2007, 28:236-43. 10.1016/j.tips.2007.03.002

158. Tully DC, Rucker PV, Chianelli D, et al.: Discovery of tropifexor (LJN452), a highly potent non-bile acid FXR agonist for the treatment of cholestatic liver diseases and nonalcoholic steatohepatitis (NASH). J Med Chem. 2017, 60:9960-73. 10.1021/acs.jmedchem.7b00907

159. Chianelli D, Rucker PV, Roland J, et al.: Nidufexor (LMB763), a novel FXR modulator for the treatment of nonalcoholic steatohepatitis. J Med Chem. 2020, 63:3868-80. 10.1021/acs.jmedchem.9b01621

160. Romere C, Duerrschmid C, Bournat J, et al.: Asprosin, a fasting-induced glucogenic protein hormone. Cell. 2016, 165:566-79. 10.1016/j.cell.2016.02.063

161. Duerrschmid C, He Y, Wang C, et al.: Asprosin is a centrally acting orexigenic hormone. Nat Med. 2017, 23:1444-53. 10.1038/nm.4432

162. Mishra I, Duerrschmid C, Ku Z, et al.: Asprosin-neutralizing antibodies as a treatment for metabolic syndrome. Elife. 2021, 10:e63784. 10.7554/eLife.63784

163. Amato G, Khan NS, Maitra R: A patent update on cannabinoid receptor 1 antagonists (2015-2018) . Expert Opin Ther Pat. 2019, 29:261-9. 10.1080/13543776.2019.1597851

164. Chorvat RJ: Peripherally restricted CB1 receptor blockers . Bioorg Med Chem Lett. 2013, 23:4751-60. 10.1016/j.bmcl.2013.06.066

165. Christensen R, Kristensen PK, Bartels EM, Bliddal H, Astrup A: Efficacy and safety of the weight-loss drug rimonabant: a meta-analysis of randomised trials. Lancet. 2007, 370:1706-13. 10.1016/S01406736(07)61721-8

166. Klumpers LE, Fridberg M, de Kam ML, et al.: Peripheral selectivity of the novel cannabinoid receptor antagonist TM38837 in healthy subjects. Br J Clin Pharmacol. 2013, 76:846-57. 10.1111/bcp.12141 
167. Ma H, Zhang G, Mou C, Fu X, Chen Y: Peripheral CB1 receptor neutral antagonist, AM6545, ameliorates hypometabolic obesity and improves adipokine secretion in monosodium glutamate induced obese mice. Front Pharmacol. 2018, 9:156. 10.3389/fphar.2018.00156

168. Chorvat RJ, Berbaum J, Seriacki K, McElroy JF: JD-5006 and JD-5037: peripherally restricted (PR) cannabinoid-1 receptor blockers related to SLV-319 (Ibipinabant) as metabolic disorder therapeutics devoid of CNS liabilities. Bioorg Med Chem Lett. 2012, 22:6173-80. 10.1016/j.bmcl.2012.08.004

169. Zhang Z, Mocanu V, Cai C, et al.: Impact of fecal microbiota transplantation on obesity and metabolic syndrome-a systematic review. Nutrients. 2019, 11:2291. 10.3390/nu11102291

170. Ridaura VK, Faith JJ, Rey FE, et al.: Gut microbiota from twins discordant for obesity modulate metabolism in mice. Science. 2013, 341:1241214. 10.1126/science.1241214

171. Kootte RS, Levin E, Salojärvi J, et al.: Improvement of insulin sensitivity after lean donor feces in metabolic syndrome is driven by baseline intestinal microbiota composition. Cell Metab. 2017, 26:611-9.e6. 10.1016/j.cmet.2017.09.008

172. Vrieze A, Van Nood E, Holleman F, et al.: Transfer of intestinal microbiota from lean donors increases insulin sensitivity in individuals with metabolic syndrome. Gastroenterology. 2012, 143:913-6.e7. 10.1053/j.gastro.2012.06.031

173. de Groot PF, Frissen MN, de Clercq NC, Nieuwdorp M: Fecal microbiota transplantation in metabolic syndrome: history, present and future. Gut Microbes. 2017, 8:253-67. 10.1080/19490976.2017.1293224

174. Yang T, Santisteban MM, Rodriguez V, et al.: Gut dysbiosis is linked to hypertension. Hypertension. 2015, 65:1331-40. 10.1161/HYPERTENSIONAHA.115.05315

175. Lemus HN, Mendivil CO: Adenosine triphosphate citrate lyase: emerging target in the treatment of dyslipidemia. J Clin Lipidol. 2015, 9:384-9. 10.1016/j.jacl.2015.01.002

176. Pinkosky SL, Filippov S, Srivastava RA, et al.: AMP-activated protein kinase and ATP-citrate lyase are two distinct molecular targets for ETC-1002, a novel small molecule regulator of lipid and carbohydrate metabolism. J Lipid Res. 2013, 54:134-51. 10.1194/jlr.M030528

177. Ray KK, Bays HE, Catapano AL, et al.: Safety and efficacy of bempedoic acid to reduce LDL cholesterol . N Engl J Med. 2019, 380:1022-32. 10.1056/NEJMoa1803917

178. Markham A: Bempedoic acid: first approval. Drugs. 2020, 80:747-53. 10.1007/s40265-020-01308-W

179. Friedman JM, Halaas JL: Leptin and the regulation of body weight in mammals . Nature. 1998, 395:763-70. $10.1038 / 27376$

180. Burguera B, Couce ME, Curran GL, Jensen MD, Lloyd RV, Cleary MP, Poduslo JF: Obesity is associated with a decreased leptin transport across the blood-brain barrier in rats. Diabetes. 2000, 49:1219-23. 10.2337/diabetes.49.7.1219

181. Dube MG, Beretta E, Dhillon H, Ueno N, Kalra PS, Kalra SP: Central leptin gene therapy blocks high-fat dietinduced weight gain, hyperleptinemia, and hyperinsulinemia: increase in serum ghrelin levels. Diabetes. 2002, 51:1729-36. 10.2337/diabetes.51.6.1729 